\title{
Spatial information technology in flood early warning systems: an overview of theory, application and latest developments in Malaysia
}

\begin{abstract}
Malaysia experiences a major flood event every three years due to the adverse effects of two monsoon seasons a year. Floods have thus become the most significant natural disaster in the country in terms of the population affected, frequency, aerial extent, financial cost and the disruption to socio-economic activities. Many previous flood control measures have had different levels of success but have generally had little effect in reducing the problem. However, it is now understood that it is neither possible nor desirable to control floods completely. Spatial information technology is thus being increasingly recognized as the most effective approach to flood disaster management. This paper reviews the spatial information technology in flood disaster management and its application in Malaysia. Some flood forecasting systems are discussed, along with their shortcomings. The paper discusses the framework of a proposed flood early warning system for the Langat river basin that operationally couples real-time NOAA-AVHRR data for quantitative precipitation forecasting with hydrologically oriented GIS and a MIKE11 hydrodynamic model.
\end{abstract}

Keyword: Floods, Forecasting, Geographic information systems, Malaysia, Natural disasters 